\title{
Toward Disentangling Sources of Individual Differences in Appraisal and Anger
}

\section{Peter Kuppens, Iven Von Mechelen, and Fronk Rijmen}

\author{
Katholieke Universiteit Leuven
}

\begin{abstract}
A theoretical framework is presented to explain individual differences in situation-specific emotional experience in terms of three different sources of variance: (a) individual differences in how one appraises one's circumstances, (b) individual differences in how appraisals are related to the experience of emotion, and (c) individual differences independent from situation and appraisal. The relative contribution and nature of these sources was examined empirically for the experience of anger based on data from two directed imagery studies (total $N=1,192$ ). Consistent results across the two studies demonstrated that variability in anger experience primarily stems from variability in how a situation is appraised and to a smaller extent from individual differences in the relations between the appraisals and anger and individual differences independent of appraisal. The findings further identified frustration as the central appraisal involved in anger. Implications for emotion theories and anger management programs are discussed.
\end{abstract}

\section{We all boil at different degrees. — Ralph Waldo Emerson}

People experience anger more or less frequently during daily life. The experience of anger may result in important interpersonal and even societal consequences, both maladaptive (e.g., aggression, hostility,

The authors would like to thank Tom Snijders, Francis Tuerlinckx, and Eva Van de gaer for their comments on earlier versions of this paper. The research reported in this paper was supported by KULeuven Research Council Grant GOA/05/04. The first author is a postdoctoral research fellow of the Flemish Fund for Scientific Research (FWO).

Correspondence concerning this article should be addressed to Peter Kuppens, Department of Psychology, Katholieke Universiteit Leuven. Tiensestraat 102, 3000 Leuven, Belgium; E-mail: peter.kuppens@psy.kuleuven.be.

Journal of Personality 76:4, August 2008

(C) 2008, Copyright the Authors

Journal compilation (C) 2008, Blackwell Publishing, Inc.

DOI: $10.1111 / \mathrm{j} .1467-6494.2008 .00511 . x$ 
coronary heart disease; Spielberger et al., 1985) and adaptive (e.g., increased social status, Tiedens, 2001; ameliorated interpersonal relationships, Averill, 1983; justice behavior, Leach, Iyer, \& Pedersen, 2006). Given such profound consequences, it is important to understand the causes of anger and to examine why some individuals are more prone to experience anger in specific situations as compared to others.

Appraisal theories of emotions are generally considered as the most widespread account of the elicitation and differentiation of emotions (Scherer, 2001a). According to these theories, emotions are a function of a person's evaluations or appraisal of his or her circumstances in relation to the person's own goals, concerns, and wellbeing. Over the past two decades, appraisal research has mostly concentrated on identifying the (patterns of) appraisals that lie at the basis of the experience of specific emotions (e.g., Frijda, Kuipers, \& ter Schure, 1989; Roseman, Spindel, \& Jose, 1990; Smith \& Ellsworth, 1985; Smith \& Lazarus, 1993; for overviews, see, e.g., Omdahl, 1995; Scherer, Schorr, \& Johnstone, 2001). The appraisal contents that have been identified as involved in anger include the appraisals of motivational relevance, frustration, ${ }^{1}$ other-accountability or other-blame, and unfairness, although there is discussion about which appraisal should be seen as most defining for anger. Whereas some authors have claimed that other-blame is the core appraisal content that is associated with the experience of anger (e.g., Smith \& Lazarus, 1993), others have argued that frustration should be seen as the most crucial one (e.g., Frijda, 1993).

1. In this article, we consider the term frustration to refer to an appraisal of events, although it is sometimes used to denote an emotional state as well. Considering frustration as an appraisal dimension lines up with a vast literature. Frustration has been defined by psychology scholars as follows: "an interference with the occurrence of an instigated goal-response at its proper time in the behavioural sequence" (Dollard, Doob, Miller, Mowrer, \& Sears, 1939), "the interruption of some planned or ongoing activity" (Averill, 1983), "the blocking of a goal-directed behaviour sequence" (Scherer, 2001b), Anderson and Bushman (2002) consider frustration as a situational antecedent, defined as "the blockage of goal attainment." It is clear that the common element in these definitions is a reference to what happens in relation to a person's goal, an element that is at the core of the classic definition of an appraisal. Many authors list frustration as an important, if not the most important, cause of anger (Averill, 1983; Dollard et al., 1939; Fehr, Baldwin, Collins, Patterson, \& Benditt, 1999). For instance, Russell and Fehr (1994) list as one of the possible causes of anger "a cognitive appraisal of ... frustration" (p. 188). 
One of the original motivations for the construction of appraisal theory was to account systematically for individual differences in emotional experience, even in response to the same situation (Roseman \& Smith, 2001; Smith \& Pope, 1992). Yet, although the existence of individual differences in appraisals and emotional experience is widely acknowledged (e.g., Lazarus, 1994; Scherer, 1999; Smith \& Pope, 1992), it has received only little attention (Griner \& Smith, 2000). With this article, we will address the issue of individual differences in appraisal and emotion, in particular, anger. Our aim is to examine and disentangle the contribution of different possible sources of individual differences in the processes - appraisal and nonappraisal - that lie at the base of individual differences in anger experience. In doing so, we aim to identify the location and nature of the main origins of individual differences in emotional experience.

\section{Sources of Individual Differences in Emotional Experience}

According to appraisal theories of emotion, the occurrence of an emotion can be assumed to follow from the following psychological processes: (1) a situation is appraised by a particular person as a function of the characteristics of the situation and the person's own goals and concerns and (2) particular patterns of appraisals elicit or are associated with the experience of specific emotions (Gross \& John, 2003; Scherer et al., 2001). Thus, when a person is publicly offended, he or she can appraise the situation as frustrating and blame someone else for it, and these appraisals may cause or constitute the experience of anger.

As a result, in principle, individual differences in emotional experience can arise from three different sources (see Figure 1): (1) individual differences in how a situation is appraised and (2) individual differences in how the appraisals are associated with emotional experience. Also, it should a priori not be ruled out that (3) individual differences in emotional experience may arise from dispositional factors outside the "appraisal pathway." We will now discuss these three sources in more detail.

\section{Individual Differences in Appraisal}

By definition, the appraisal process is of a subjective nature and is therefore subject to individual differences. As a result, how people 


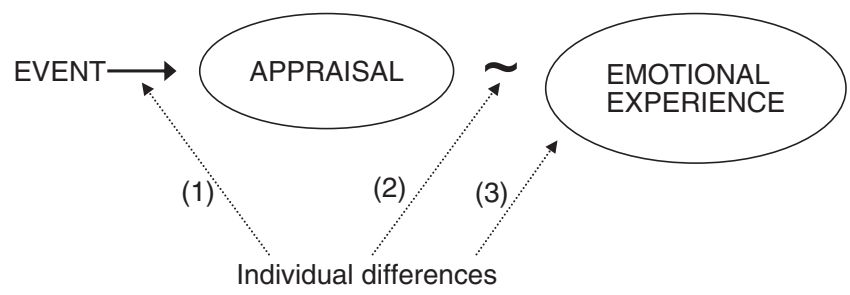

Figure 1

Possible sources of individual differences in emotional experience: (1) Individual differences in how on event is appraised, (2) individual differences in how appraisals are associated with emotional experience, and (3) individual differences in emotional experience independent of appraisal and event.

appraise their circumstances has been argued to constitute a key factor in understanding individual differences in emotion (e.g., Smith \& Pope, 1992). Yet, research directly examining individual differences in appraisal is far from abundant (Smith \& Pope, 1992; van Reekum \& Scherer, 1997). In this respect, Smith and Kirby (2001) recently stated that "relatively little work has examined the antecedents of the appraisals themselves ... nonetheless, such work is vital" (p. 122).

There are exceptions, however. Research on hostile attribution bias (Dodge, 1993) has documented that anger- and aggressionprone individuals are characterized by a tendency to attribute hostile intentions to the behavior of others (e.g., Epps \& Kendall, 1995; Graham, 1997). In general, this research highlights the role of individual differences in appraisal tendencies in emotional responding (see also, e.g., van Reekum \& Scherer, 1997; Kuppens, Van Mechelen, Smits, De Boeck, \& Ceulemans, 2007). Moreover, a few studies have investigated contextual individual differences in appraisals, that is, how individual differences in appraisal can be specific to particular types of appraisal-relevant situations (reflecting person by situation interaction; e.g., Griner \& Smith, 2000; Kuppens \& Van Mechelen, 2007; Smith \& Pope, 1992).

\section{Individual Differences in the Relation Between Appraisal and Emotion}

Several prominent appraisal theorists have argued that how an individual appraises his or her circumstances represents the sole source 
of individual differences in emotional experience because there is a fixed relation between particular appraisal patterns and emotional experience (e.g., Roseman \& Smith, 2001; Smith \& Pope, 1992). Yet there is growing evidence that this may not be the case (e.g., Kuppens, Van Mechelen, Smits, \& De Boeck, 2003; Parkinson, 1999). For instance, the appraisal of blaming someone else for what has happened is often considered a key appraisal for anger (e.g., Smith \& Lazarus, 1993). Several studies indicate, however, that when one blames oneself, the circumstances, or faith (e.g., Ellsworth \& Tong, 2006; Parkinson, 1999), anger can occur in the absence of this appraisal. Also, more generally, it has been claimed that there may be variability in the relationship between appraisal contents and emotional experience (Frijda \& Zeelenberg, 2001; Parkinson, 2001; Scherer, 2001a).

Several studies have indeed demonstrated that individual differences in these relations exist, using imagery techniques (Kuppens et al., 2007; Vansteelandt \& Van Mechelen, 2006), experience sampling (Nezlek, Van Mechelen, Vansteelandt, \& Kuppens, 2008), and in vivo experiments (Silvia, 2005). This means that a particular appraisal content may be strongly related to a particular emotional experience for one individual but not for another. In the context of anger, such individual differences would reflect differences in frustration tolerance (Buss, 2004), that is, how able one is to tolerate events appraised as frustrating without becoming angry or aggressive. Similarly, research by Meier, Robinson, and colleagues (e.g., Meier \& Robinson, 2004; Meier, Robinson, \& Wilkowski, 2006) examined individual differences in the self-regulation of hostile thoughts and revealed that people differ in the level of displayed aggression following blame- and aggression related contents. Such findings seem to suggest that people can differ in how they regulate their emotional reactions to emotion-eliciting contents, with some being more able to regulate or "cool down" their anger as opposed to others. It is clear that such differences can also contribute to individual differences in emotional experience.

\section{Sources of Individual Differences Independent From Appraisal}

It should not be ruled out that factors other than those comprised in the appraisal pathway described above influence emotional experience. According to the neoassociationistic theory of Berkowitz 
(1990; Berkowitz \& Harmon-Jones, 2004), anger is primarily produced by mere aversive stimulation, in absence of the appraisal processes that are generally considered to be involved in its elicitation, and people show individual differences in how easily they are angered in the absence of such appraisals. In this respect, it has indeed been shown that people differ in how easily they experience anger and act aggressively in nonprovoking circumstances (Bettencourt, Talley, Benjamin, \& Valentine, 2006). Such differences may thus reflect individual differences in general aggression and angerproneness that is independent of appraisal processes and can be expected to contribute to variability in anger experience.

\section{The Present Study}

The aim of the present article is to disentangle the contributions of these different sources of variability in anger experience by determining to what extent the variability in anger experience is due to (1) individual differences in how individuals appraise their circumstances, to (2) individual differences in how these appraisals are related to the experience of anger, and, finally, to (3) individual differences unrelated to appraisal. From a theoretical point of view, such knowledge would significantly add to our understanding of the processes underlying emotional experience. From a clinical point of view, it could provide important information for the development of emotion management programs.

Additionally, we aim to examine the nature of the found sources of individual differences by examining their interrelations as well as their relation with trait-anger - a disposition reflecting the general proneness to experience anger. Trait-state theory holds that individuals differ with respect to stable dispositions that cause them to experience particular emotions more intensely and frequently (e.g., Bettencourt et al., 2006; Deffenbacher, 1992). Examining the relationships between trait-anger and the above mentioned sources of individual differences in situation-specific (state) emotional experience could therefore yield valuable insight into the processes underlying trait-state relationships. In general, research has demonstrated that individuals are more sensitive (in terms of experiencing higher levels) and responsive (in terms of reacting more strongly) to states that match their dispositions. For instance, neurotics experience more negative events and are also more reactive to such events (e.g., 
Larsen \& Ketelaar, 1991). Following such a disposition-stimulus match hypothesis, we expect trait-anger to be related to heightened anger appraisal tendencies such as the tendency to appraise one's circumstances as frustrating or as caused by someone else and to a greater reactivity to these appraisals (in terms of the strength of appraisal-anger relationships). Additionally, we will examine if traitanger is also related to individual differences in anger regardless of appraisal.

To this end, we will reanalyze self-report data of appraisals and anger taken from two directed imagery studies. We propose a new method to analyze the nested data structures obtained in these studies to answer the central questions at hand. The proposed method was specifically tailored to address our research questions but also provides a general framework to disentangle the contributions of sequential processes in other domains of research.

\section{STUDY 1}

The aim of this study is to obtain a first and reliable quantification of the contribution of the different possible sources of individual differences to the experience of anger. To this end, data from a directed imagery study by Kuppens et al. (2007) were reanalyzed in light of the current research questions. ${ }^{2}$ Although based on reactions to hypothetical scenarios, research has shown that this imagery method can inform theory formation on appraisal and emotion in valid ways and that the obtained information about appraisal and appraisalemotion relationships are similar to those using other methods (Robinson \& Clore, 2001). In this study we focus on the appraisals of frustration, other-accountability, and unfairness. The participants in the study consisted of a large $(N=832)$ number of final-year high school students. The large sample size enables a reliable quantification of the contribution of the different sources of individual differences. Moreover, the use of a heterogeneous sample of high school students limits generalizability problems that may arise when using a specific sample of participants (e.g., psychology students) and guarantees to capture a large range of the natural variation that occurs with respect to the domain of study.

2. This study was originally set up to examine individual differences in necessity and sufficiency relationships between appraisals and anger. 


\section{Method}

\section{Participants}

Participants were 832 senior high school students from eight different high schools located in small-city areas in the Dutch speaking part of Belgium; 546 of the participants were girls, 286 boys (mean age $=17.1$ years).

\section{Materials and Procedure}

Situation descriptions. In an earlier study, Kuppens et al. (2003) collected a total of 443 situation descriptions from 161 high school students. Each participant had to describe three recently experienced unpleasant situations from three different life domains (work or school, interpersonal contact, leisure) that were characterized by either the presence or absence of one of the following six features: frustration, other-accountability, arrogant entitlement, antagonistic action tendency, anger, irritation. From the resulting pool of situation descriptions, 24 descriptions were selected for use in the present study. The selection required that (a) two situations were sampled from each of the 12 instruction types under which the situations were generated, (b) the three domains of life were equally represented, and (c) an equal proportion of male and female participants that generated the situations. This method enabled the construction of a list with a broad array of situation descriptions (see Appendix A) that are relevant for the participants (high-school students).

Anger and appraisal items. The item "To what degree do you feel angry in this situation?" measured the experience of anger. Regarding the appraisal items, a pilot study was performed to select reliable and valid item formulations that reflect anger-relevant appraisal contents (for details, see Kuppens et al., 2007). The formulations that were retained were: "To what extent are you frustrated in this situation?" (frustration); "Do you feel that someone else is deliberately accountable for what has happened?" (other-accountability); "Do you feel treated in an unfair way?" (unfairness).

Trait-anger. The Dutch adaptation of the Spielberger trait-anger scale (van der Ploeg, Defares, \& Spielberger, 1982) was administered to a subset of 628 participants to assess general anger proneness. This scale consists of 10 items reflecting general anger-proneness that have to be rated on a 4-point scale (ranging from $0=$ almost never to $3=$ almost always). The scale proved to be internally consistent (Cronbach's alpha $=.85$ ). The average score was $1.27(S D=0.58$, Min. $=0$, Max. $=3)$. 
The study was conducted in small groups of up to 30 participants each. For each situation description, the participants were instructed to imagine vividly how they would feel, think, and act if they found themselves in the situation and to rate their reaction on the anger and appraisal items using a 4-point scale (ranging from $0=$ not at all, to $3=$ very strong). Subsequently, participants filled out the trait-anger scale. Several versions of the imagery task were constructed, in which the order of the items was counterbalanced, as well as whether the appraisal and anger items were presented jointly or separately (in which case, the situation descriptions were presented twice). Preliminary analyses revealed no substantial systematic effects of these manipulations for our primary research questions, and the data were further analyzed jointly.

\section{Analyses}

The data obtained via the directed imagery task have a nested structure with appraisal and anger ratings for situations being nested within persons (with situations being fully crossed with persons). The data were analyzed using a conjunction of multivariate analysis of variance of the appraisal scores (MANOVA; for an introduction, see, e.g., Bray \& Maxwell, 1985) and mixed (multilevel) regression modeling (for introductions, see, e.g., Nezlek, 2001; Snijders \& Bosker, 1999). First, the fully crossed nature of the data allow us to produce estimates of the variances and covariances of the individual differences variability, situational variability, and person by situation interaction (plus error) of the appraisals $\left(X_{a}\right)$ based on the mixed effects MANOVA model given by the following expression

$$
\begin{aligned}
& X_{1 i j}=\mu_{1}+\alpha_{1 i}+V_{1 j}+\varepsilon_{1 i j}^{X} \\
& \ldots \\
& X_{a i j}=\mu_{a}+\alpha_{a i}+V_{a j}+\varepsilon_{a i j}^{X} \\
& \ldots \\
& X_{p i j}=\mu_{p}+\alpha_{p i}+V_{p j}+\varepsilon_{p i j}^{X} \\
& \text { with }\left\{\begin{array}{l}
V_{j} \sim \operatorname{MVN}\left(0, \Sigma_{\mathrm{V}}\right) \\
\varepsilon_{i j}^{X} \sim \operatorname{MVN}\left(0, \Sigma_{\varepsilon}\right)
\end{array}\right.
\end{aligned}
$$

in which $i$ denotes the $i$-th situation, $j$ the $j$-th person, and $a$ the $a$-th appraisal. $\mu_{a}$ represents the overall mean of appraisal $a ; \alpha_{a i}$ represents the contribution of situation $i$ to appraisal $a, V_{a j}$ reflects the contribution of person $j$, and $\varepsilon_{a i j}^{X}$ reflects the contribution of the person by situation 
interaction plus error (for partitioning into variance components in MANOVA, see Bock, 1975).

Second, in a mixed regression model, anger scores are predicted on the basis of the (centered) appraisal scores of frustration, other-accountability, and unfairness, allowing for person-specific ("random") intercept and slope values. This model is given by the expression

$$
Y_{i j}=\gamma_{0}+U_{0 j}+\sum_{a=1}^{P}\left(\gamma_{a} X_{a i j}+U_{a j} X_{a i j}\right)+\varepsilon_{i j}
$$

$Y_{i j}$ denotes the anger score of person $j$ in situation $i$, and $X_{a i j}$ the score of person $i$ in situation $j$ for appraisal $a ; \gamma_{0}$ and $\gamma_{a}$ denote the fixed intercept and slope values, respectively; $U_{0 j}$ and $U_{a j}$ denote the random, personspecific (as appears from the $j$-subscript) intercept and slope values, respectively; $\varepsilon_{i j}$ denotes the residual variance. From this model, estimates of the $\gamma$ 's and of the (co)variances of $U_{0 j}, U_{a j}$, and $\varepsilon_{i j}$ are obtained.

Third, making the standard assumption of independence between $\left(U_{0 j}\right.$, $\left.U_{a j}\right)$ on the one hand and $\left(X_{a i j}\right)$ on the other hand, it can be shown that the estimates from the two models can be used to decompose the total variance in $Y$ (anger) as follows:

$$
\begin{aligned}
\operatorname{Var}\left(Y_{i j}\right)= & \sum_{a=1}^{p} \sum_{b=1}^{p} \gamma_{a} \gamma_{b}\left[\operatorname{COV}\left(\alpha_{a i}, \alpha_{b i}\right)+\operatorname{COV}\left(V_{a j}, V_{b j}\right)+\operatorname{COV}\left(\varepsilon_{a i j}^{X}, \varepsilon_{b i j}^{X}\right)\right] \\
& +\sum_{a=1}^{p} \sum_{b=1}^{p} \operatorname{COV}\left(U_{a j}, U_{b j}\right) \operatorname{COV}\left(X_{a i j}, X_{b i j}\right)+\operatorname{Var}\left(U_{0 j}\right)+\operatorname{Var}\left(\varepsilon_{i j}^{Y}\right)
\end{aligned}
$$

This decomposition directly corresponds to the different sources of individual differences of interest: (1) The first term reflects the total contribution of how people appraise their circumstances to the variability in anger, which is further broken down into the contributions of individual differences (reflecting appraisal tendencies or the fact that people consistently tend to appraise their circumstances differently), of situational differences (reflecting the situation main effect or the fact that different circumstances can pull for different characteristic appraisals), and of person by situation interaction (reflecting the fact that individuals can be idiosyncratic in how they appraise certain types of situations), plus error. (2) The second term reflects the contribution of individual differences in the strength with which the appraisals are related to anger. (3) The third term reflects the contribution of individual differences in the experience of anger independent of the appraisals. Finally, the last term represents the portion of variance in anger unexplained by the model. 


\section{Results}

First, the results from the MANOVA revealed that individual differences (person main effect) and situation differences (situation main effect) seem to account for an equally large part of the variance in frustration (each 25\%), whereas for other-accountability and unfairness the contribution of situation differences $(45 \%$ and $46 \%$, respectively) is considerably larger than that of individual differences (12\% and $13 \%$, respectively). This implies that for all three appraisals, the person by situation interaction (plus error) plays a substantial role as well (ranging from $41 \%$ to $50 \%$ ).

Second, the results from the mixed model regression analysis (Table 1) revealed that across all participants, all three appraisals are significant predictors of anger, with frustration emerging as the strongest predictor. Furthermore, the significant amount of variability in the intercept and slope values points to the existence of significant individual differences in anger experience irrespective of appraisal and in the appraisal-anger links, respectively. Individuals with a slope about $2 S D$ below the mean slope for a particular appraisal are characterized by a near lack of association between that appraisal and anger, whereas individuals positioned about $2 S D$ above the mean are characterized by a very strong association between the appraisal and anger.

\section{Table 1}

Results of Mixed Regression Analysis Predicting Anger on the Basis of the Appraisals Frustration, Other-Accountability, and Unfairness (Study 1)

\begin{tabular}{lcrrr}
\hline Parameter & Coefficient & $T$ ratio & $S D$ & $\chi^{2}$ value $^{\mathrm{a}}$ \\
\hline Intercept & 1.39 & $134.24^{* * * * *}$ & 0.25 & $949.81^{* * * * *}$ \\
Frustration & 0.43 & $45.66^{* * * *}$ & 0.21 & $494.49^{* * * * *}$ \\
Other-accountability & 0.20 & $25.57^{* * * *}$ & 0.12 & $81.02^{* * * *}$ \\
Unfairness & 0.27 & $30.64^{* * * *}$ & 0.15 & $165.40^{* * * *}$ \\
\hline
\end{tabular}

Note.

$* * * * p<.001$.

${ }^{\text {a }}$ The $\chi^{2}$ value is calculated as the difference between $-2 \times \operatorname{LogLikelihood~(devi-~}$ ance) of a model including and a model excluding the random term; associated $p$ values were calculated on the basis of a mixture $\chi^{2}$-sampling distribution (Molenberghs \& Verbeke, 2004). 
Third, addressing our central research question, the estimates from both previous analyses were combined, and the (relative) contributions of the different sources of variance to the experience of anger were derived (Table 2). The results show that how events are appraised (Link 1 in Figure 1) clearly explains the largest part of the variance in anger $(53 \%)$. Within this link, about equally important contributions are to be attributed to situational differences in appraisal and to the person by situation interaction (plus error), with the contribution of global individual differences in appraisal tendencies being somewhat lower. Next, individual differences in appraisal-anger relationships (Link 2 in Figure 1) represent clearly a smaller contribution. Likewise, a small contribution was observed for individual differences independent from appraisal (Link 3 in Figure 1). The residual on the final line represents the amount of variability not explained by the model.

Finally, we examined the interrelations between the various sources of individual differences as well as their relations with trait-anger. For this purpose, we calculated correlations between appraisal tendencies (participants' appraisal scores averaged across all 24 situations) and individual differences in appraisal-anger relations and

\section{Table 2}

Contributions of Sources of Individual Differences to Anger Experience (Study 1)

\begin{tabular}{|c|c|c|}
\hline & Variance & $\%$ \\
\hline \multicolumn{3}{|l|}{ Appraisal (fixed part) ${ }^{\mathrm{a}}$} \\
\hline Person & 0.14 & $11 \%$ \\
\hline Situation & 0.30 & $22 \%$ \\
\hline $\mathrm{P} \times \mathrm{S}$ (plus error) & 0.28 & $21 \%$ \\
\hline Total & 0.71 & $53 \%$ \\
\hline Appraisal-emotion (random slope) ${ }^{\mathrm{b}}$ & 0.06 & $4 \%$ \\
\hline Nonappraisal sources (random intercept) ${ }^{\mathrm{c}}$ & 0.06 & $5 \%$ \\
\hline Residual & 0.49 & $37 \%$ \\
\hline \multicolumn{3}{|c|}{$\begin{array}{l}\text { a This part represents the contribution of how events are appraised, broken down } \\
\text { into contributions from person, situation, and person by situation interaction (plus } \\
\text { error). } \\
{ }^{\mathrm{b}} \text { This part represents the contribution of individual differences in appraisal-emotion } \\
\text { relationships. } \\
{ }^{\mathrm{c}} \text { This part represents the contribution of individual differences in anger regardless of } \\
\text { appraisal. }\end{array}$} \\
\hline
\end{tabular}


individual differences in anger regardless of appraisal (which are available as the person-specific slope and intercept estimates from the mixed regression model) (see Table 3). Large positive correlations were observed among the three appraisal tendencies, whereas correlations between appraisal tendencies and appraisalanger relationships were of a more modest nature. Large negative correlations were observed between individual differences in the frustration-anger relation on the one hand and individual differences in the other-accountability-anger and unfairness-anger relations on the other hand. Finally, individual differences in anger, independent from appraisal, was positively related to the strength of frustration-anger relationships, and, negatively, to the strength of unfairness-anger relationships. Regarding relationships with traitanger, the appraisal tendencies all showed positive correlations with trait-anger (Table 3). Furthermore, trait-anger was significantly, but

\section{Table 3}

Correlations Between Individual Differences in Appraisal Tendencies (Appraisal Scores Averaged Across 24 Situations), Appraisal-Anger Relations (Person-Specific Slope Values), Anger Regardless of Appraisal (Person-Specific Intercept Values), and Trait-Anger (Study 1)

\begin{tabular}{|c|c|c|c|c|c|c|c|}
\hline & 2. & 3. & 4. & 5. & 6. & 7. & 8. \\
\hline $\begin{array}{l}\text { 1. Frustration } \\
\text { appraisal tendency }\end{array}$ & $.56^{* * * * *}$ & $.63^{* * * *}$ & $.23^{* * * *}$ & $-.19^{* * * *}$ & $-.15^{* * * *}$ & $-.21^{* * * *}$ & $.36^{* * * * *}$ \\
\hline $\begin{array}{l}\text { 2. Other-accountability } \\
\text { appraisal tendency }\end{array}$ & & $.81^{* * * *}$ & .02 & -.03 & $-.09 * *$ & $-.15^{* * * *}$ & $.30 * * * *$ \\
\hline $\begin{array}{l}\text { 3. Unfairness appraisa } \\
\text { tendency }\end{array}$ & & & -.02 & $-.11 * *$ & .01 & $-.15^{* * * *}$ & $.30 * * * *$ \\
\hline $\begin{array}{l}\text { 4. Frustration-anger } \\
\text { relation }\end{array}$ & & & & $-.54 * * * *$ & $-.77 * * * *$ & $.36 * * * *$ & $.10^{*}$ \\
\hline $\begin{array}{l}\text { 5. Other-accountability- } \\
\text { anger relation }\end{array}$ & & & & & .06 & $.11^{* * *}$ & -.03 \\
\hline $\begin{array}{l}\text { 6. Unfairness-anger } \\
\text { relation }\end{array}$ & & & & & & $-.27^{* * * *}$ & $-.09 *$ \\
\hline $\begin{array}{l}\text { 7. Anger regardless of } \\
\text { appraisal }\end{array}$ & & & & & & & .06 \\
\hline 8. Trait-anger & & & & & & & \\
\hline
\end{tabular}

${ }^{*} p<.05 .{ }^{* *} p<.01 . * p<.001$. 
only weakly, related to individual differences in the frustration-anger relationships and negatively to individual differences in unfairnessanger relationships.

\section{Discussion}

In line with standard appraisal theory assumptions, variability in the experience of anger was for the largest part accounted for by sources stemming from the appraisal pathway. A total of $57 \%$ of anger variability was related to appraisal sources. Importantly, in the appraisal pathway, the bulk of variability in anger stemmed from variability in how a situation is appraised by an individual (Link 1 in Figure 1), with the appraisal of frustration clearly playing the most important role in anger prediction.

Individual differences in the tendencies to appraise one's circumstances as frustrating, caused by someone else, and unfair were highly interrelated, revealing a general pessimistic appraisal tendency dimension. The fact that the different appraisal tendencies were highly related may suggest that hostile attribution bias (e.g., Graham, 1997) may be part of a more general pessimistic, anger-eliciting appraisal bias. Moreover, such a tendency may be partly responsible for the observed trait-state relationships in the domain of anger, as all three appraisal tendencies were found to be strongly related to trait-anger.

In the appraisal pathway, a nonnegligible part of anger variability could also be attributed to individual differences in how strong the appraisals are associated with anger (Link 2 in Figure 1) although the contribution of these differences is of a more modest order of magnitude than that pertaining to the first link. Nevertheless, this finding does demonstrate that part of the variability in anger experience stems from differences between individuals in how particular appraisals are associated with anger experience, which is at odds with appraisal accounts that posit invariable relationships between appraisals and emotional experience. Of interest, negative relationships were obtained between individual differences in the frustrationanger relation and individual differences in the other-accountability/ unfairness-anger relations. This suggests that individuals whose anger is strongly contingent on frustration may be less susceptible to interpersonal judgments and vice versa. Interestingly, individuals high in trait anger were more responsive to frustration but less responsive to unfairness, whereas their low trait anger counterparts 
were more responsive to unfairness and less responsive to frustration. Finally, the results demonstrated that a small but nonnegligible amount of variance in anger was due to systematic individual differences independent of the appraisal process (Link 3). These individual differences were unrelated to trait-anger, however.

Although this first study was based on a large sample of participants, a wide variety of unpleasant situations, and carefully constructed appraisal items, it may be that the obtained results were specific to the appraisal items used and/or situation descriptions (resulting in possibly biased estimates of the different contributions). Because of this, it was important to obtain a replication of the findings with other appraisal and situation materials.

\section{STUDY 2}

The main aim of this study was to replicate the findings of the first study. As in Study 1, Study 2 relied on a directed imagery task (taken from Kuppens and Van Mechelen, 2007), ${ }^{3}$ but this second study differed in a number of important ways from Study 1. First, other appraisal items formulations were used, chosen to reflect the anger appraisals in the influential appraisal model of Smith and Lazarus (1993): motivational relevance, motivational incongruence (frustration), and other-accountability. Second, we used a different set of descriptions of unpleasant situations, allowing us to check whether the findings from Study 1 generalized to other sets of circumstances. A measure of trait-anger was again included.

\section{Method}

\section{Participants}

360 psychology students enrolled at Leuven University participated in return for course credits. The sample consisted of 299 females and 61 males, with an average age of 18.65 years.

\section{Materials and Procedure}

Situation vignettes. A list of 24 situation descriptions was taken from Kuppens and Van Mechelen (2007), depicting unpleasant situations easily

3. Part of these data were also reported in Kuppens and Van Mechelen (2007) in which the determinants of the appraisals themselves were the subject of study. 
encountered by university students during daily life. The descriptions were constructed to reflect a broad range of unpleasant events that may or may not elicit several anger-related appraisals (see Appendix B).

Anger and appraisal items. The item "To what degree do you feel anger in this situation?" measured the experience of anger. Several appraisal items were assessed. The ones relevant for the present purpose are "To what degree is what is happening in this situation important to you?" (motivational relevance), "To what degree is this situation frustrating to you?" (frustration), and "To what degree do you blame someone else for what has happened in this situation" (other-accountability).

Trait-anger. Trait-anger was measured by means of the Dutch adaptation of the 10-item Spielberger Trait-anger Scale (van der Ploeg et al., 1982). Internal consistency (Cronbach's alpha) equaled .87. The average score was $1.23(S D=0.57$, $\operatorname{Min}=0, \operatorname{Max}=2.9)$.

Participants were instructed to read each situation description attentively and imagine how they would feel, think, and what they would do in such a situation. Subsequently, they rated the anger and appraisal items on a 7 -point scale (from $0=$ not at all to $6=$ very strong). The presentation order was not counterbalanced in this study. Following the imagery task, they filled out the trait-anger scale.

\section{Results}

The data were analyzed using the same procedure as in Study 1 . First, a MANOVA on the appraisal scores revealed that frustration is determined almost equally by person (28\%) and situation $(27 \%)$ main effects, whereas motivational relevance and other-accountability are more determined by the situation ( $34 \%$ and $41 \%$, resp.) than by the person ( $21 \%$ and $18 \%$, resp.). The contribution of the interaction plus error is thus also substantial for all three appraisals (ranging from $41 \%$ to $45 \%$ ).

Second, the results from the mixed model regression analysis predicting anger on the basis of motivational relevance, frustration, and other-accountability show that all appraisals contribute significantly to the prediction of anger, with frustration again emerging as the strongest predictor (Table 4). Moreover, as in Study 1, both the intercept and slopes for the three appraisals in predicting anger are characterized by a significant degree of variability, indicating the existence of systematic individual differences in anger experience 
Table 4

Results of Mixed Regression Analysis Predicting Anger on the

Basis of Motivational Relevance, Frustration, and Other-Accountability (Study 2)

\begin{tabular}{lcrrr}
\hline Parameter & Coefficient & $T$ ratio & $S D$ & $\chi^{2}$ value $^{\mathrm{a}}$ \\
\hline Intercept & 3.95 & $134.42^{* * * *}$ & 0.50 & $906.01^{* * * * *}$ \\
Motivational relevance & 0.25 & $21.11^{* * * *}$ & 0.13 & $73.50^{* * * *}$ \\
Frustration & 0.56 & $40.85^{* * * *}$ & 0.18 & $218.44^{* * * *}$ \\
Other-accountability & 0.19 & $19.24^{* * * *}$ & 0.13 & $191.84^{* * * *}$ \\
\hline
\end{tabular}

Note:

$* * * * p<.001$.

${ }^{\text {a }}$ The $\chi^{2}$ value is calculated as the difference between $-2 \times$ LogLikelihood (deviance) of a model including and a model excluding the random term; associated $p$-values were calculated on the basis of a mixture $\chi^{2}$-sampling distribution (Molenberghs \& Verbeke, 2004).

regardless of appraisal and in the relations between the appraisals and anger, respectively.

Third, the (relative) contributions of the different sources of variance to the experience of anger were calculated (Table 5). The largest part of the variance in anger is explained by the fixed part of the model, that is, by the appraisal of the situation (Link 1 in Figure 1). Within this part, roughly comparable contributions of the person, the situation, and the interaction between both can be distinguished. Smaller, but nonnegligible contributions were obtained for individual differences in the relations between the appraisals and anger experience (Link 2 in Figure 1) and for individual differences independent from appraisal (Link 3 from Figure 1).

Fourth, the correlations between appraisal tendencies, appraisalanger relations, and anger regardless of appraisal were calculated (Table 6). Again, the appraisal tendencies show substantial positive interrelations. Furthermore, individual differences in the frustrationanger relation were negatively related to individual differences in the motivational relevance-anger and other-accountability-anger relations, and positively to anger regardless of appraisal. Regarding the relationships with trait anger, all appraisal tendencies again showed positive correlations with trait anger (Table 6). A moderate positive correlation was again observed between trait anger and individual differences in frustration-anger relations and a negative correlation 


\section{Table 5}

Contributions of Sources of Individual Differences to Anger

Experience (Study 2)

\begin{tabular}{lcc}
\hline & Variance & $\%$ \\
\hline Appraisal (fixed part) $^{\mathrm{a}}$ & 2.27 & \\
$\quad$ Person & 0.62 & $17 \%$ \\
Situation & 0.74 & $20 \%$ \\
$\mathrm{P} \times \mathrm{S}$ (plus error) & 0.90 & $24 \%$ \\
Total & 2.27 & $61 \%$ \\
Appraisal-emotion (random slope) $^{\mathrm{b}}$ & 0.13 & $4 \%$ \\
Nonappraisal sources (random intercept) $^{\mathrm{c}}$ & 0.26 & $7 \%$ \\
Residual $^{\mathrm{a}}$ & 1.05 & $28 \%$ \\
\hline
\end{tabular}

${ }^{\text {a }}$ This part represents the contribution of how events are appraised, broken down into contributions from person, situation, and person by situation interaction (plus error).

${ }^{\mathrm{b}}$ This part represents the contribution of individual differences in appraisal-emotion relationships.

${ }^{\mathrm{c}}$ This part represents the contribution of individual differences in anger regardless of appraisal.

was observed between trait anger and individual differences in the relation between other-accountability and anger. These relationships are graphically depicted in Figure 2 and illustrate that higher levels of trait-anger are associated with greater frustration-reactivity, but with diminished reactivity to blame. Finally, trait-anger showed a moderate positive correlation with individual differences in anger regardless of appraisal. ${ }^{4}$

\section{Discussion}

With respect to our central research questions, the results of this second study clearly replicated those from the first study. Using different situation descriptions and the appraisal model from Smith

4. Some results involving correlations with appraisal-emotion relationships (slopes) and anger regardless of appraisal (intercept) were inconsistent with Study 1. It is important to underscore that the corresponding estimates represent relationships controlled for covariation with the other appraisals in the model (similar to semipartial correlations). Given that the sets of appraisals were different in the two studies, these results are thus not directly comparable. 
Table 6

Correlations Between Individual Differences in Appraisal Tendencies (Appraisal Scores Averaged Across 24 Situations), Appraisal-Anger Relations (Person-Specific Slope Values), Anger Regardless of Appraisal (Person-Specific Intercept Values), and Trait-Anger (Study 2)

\begin{tabular}{|c|c|c|c|c|c|c|c|}
\hline & 2. & 3. & 4. & 5. & 6. & 7. & 8. \\
\hline $\begin{array}{l}\text { 1. Motivational } \\
\text { relevance appraisal } \\
\text { tendency }\end{array}$ & $.58^{* * * * *}$ & $.52^{* * * * * *}$ & .06 & .00 & -.07 & -.07 & $.20^{* * * * *}$ \\
\hline $\begin{array}{l}\text { 2. Frustration appraisal } \\
\text { tendency }\end{array}$ & & $.64^{* * * * * *}$ & .07 & $.17^{* * *}$ & $-.23 * * * *$ & $.12 *$ & 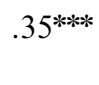 \\
\hline $\begin{array}{l}\text { 3. Other-accountability } \\
\text { appraisal tendency }\end{array}$ & & & .03 & $.22 * * * *$ & $-.26^{* * * * *}$ & $.17 * *$ & $.29^{* * * * *}$ \\
\hline $\begin{array}{l}\text { 4. Motivational } \\
\text { relevance-anger slope }\end{array}$ & & & & $-.53^{* * * *}$ & $-.19 * * * *$ & $-.18^{* * * * *}$ & .03 \\
\hline $\begin{array}{l}\text { 5. Frustration-anger } \\
\text { slope }\end{array}$ & & & & & $-.65^{* * * *}$ & $8 * * * *$ & $.33^{* * * * *}$ \\
\hline $\begin{array}{l}\text { 6. Other-accountability- } \\
\text { anger slope }\end{array}$ & & & & & & $-.46^{* * * *}$ & $.26^{* * * * *}$ \\
\hline $\begin{array}{l}\text { 7. Anger regardless of } \\
\text { appraisal (intercept) }\end{array}$ & & & & & & & $.35^{* * * * *}$ \\
\hline 8. Trait-anger & & & & & & & \\
\hline
\end{tabular}

and Lazarus (1993), it was observed that how people appraise their circumstances again proved to be the most important factor in determining how angry people felt. Again, the results showed that frustration was particularly superior in predicting anger compared to the other appraisals. It should be clear that frustration cannot be regarded as equivalent to anger. The other appraisals always showed unique contributions above frustration in explaining anger, and there remains substantial unexplained variance as well.

Apart from how individuals appraised their circumstances, variability in anger was also partly explained by individual differences in how strong the appraisals were associated with the experience of anger. In this respect, trait-anger was found to be positively related to the strength of association between frustration and anger, implying a relation between trait-anger and a lack of frustration tolerance 

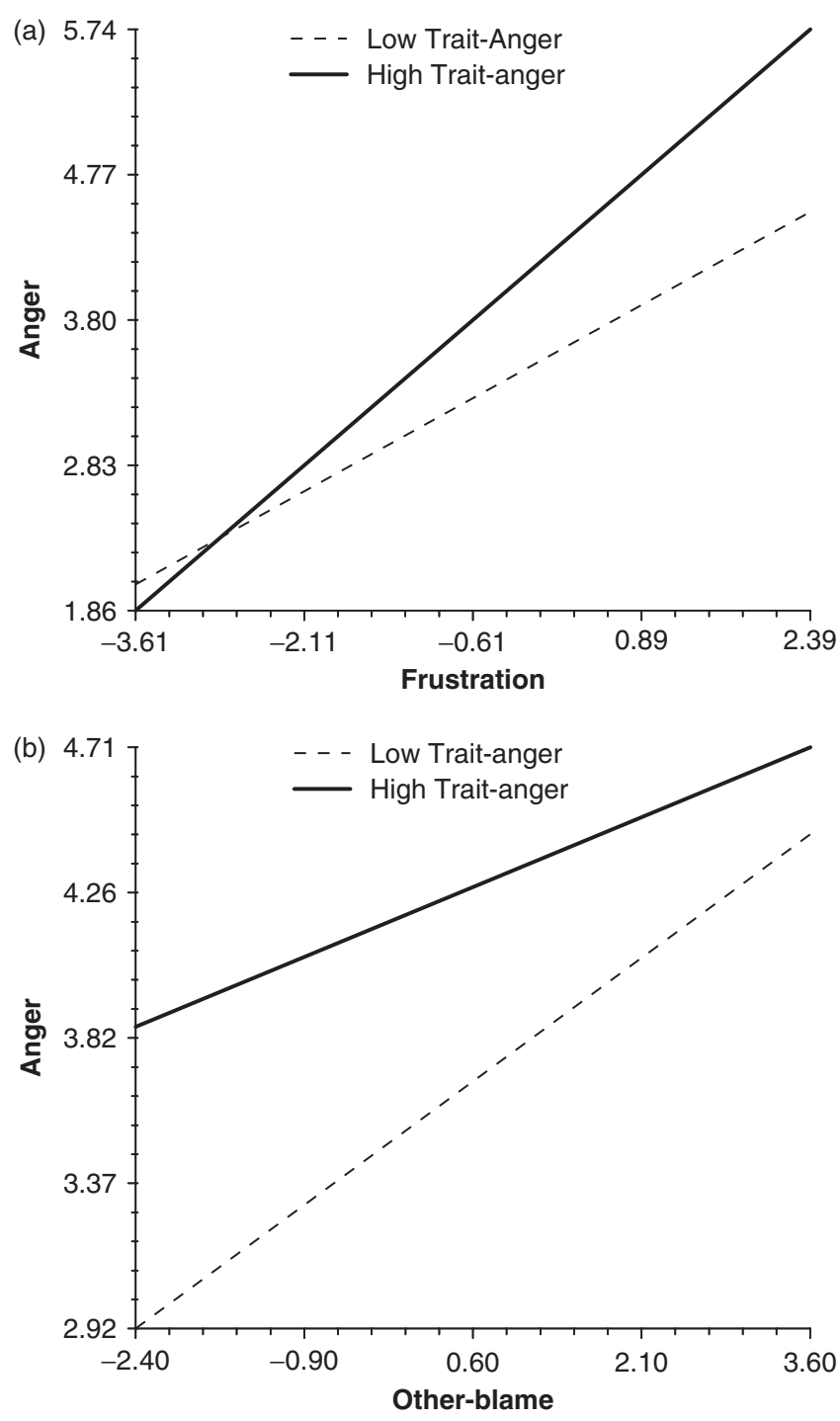

Figure 2

Prediction of anger on the basis of appraisal of (a) frustration, and (b) other-blame for low $(-2 S D)$ and high $(+2 S D)$ trait-anger individuals (Study 2).

(see also, Martin \& Dahlen, 2004). Conversely, trait-anger was negatively related to reactivity to blaming others (Figure 2). As Figure 2 reveals, this finding actually implies that high trait-anger individuals 
experience chronically higher levels of anger almost regardless of how much they blame someone for the unpleasant situation. Taken together, these results suggest that for low trait-anger individuals the actions of others strongly determine their anger experience, whereas high trait-anger individuals' anger experience is more contingent on the degree of frustration they encounter. Figure 2 also reveals that low-trait anger individuals experience lower levels of anger than high-trait anger individuals in the presence of the same levels of blame appraisals. This resonates with recent findings by Wilkowski and Robinson (2007) that low trait-anger individuals are more capable of "cooling" their anger feelings in the presence of hostile thoughts. Finally, as in Study 1, part of the variability in anger experience was due to individual differences regardless of appraisal. The finding that these differences were now found to be positively related to trait-anger was not consistent with Study 1, however.

\section{GENERAL DISCUSSION}

\section{Implications for Appraisal Theories of Emotion}

Across the two studies, the results confirmed the central role of appraisal in the experience of emotions posited by appraisal theories. The appraisals generally held as central to anger proved to be strong predictors of anger experience. Moreover, the largest portion of variance in anger experience was captured by how people appraise their environment. This clearly supports the central assumption of appraisal theories. Individual differences in this respect can take the form of general appraisal tendencies, systematic distortions, or sensitivities that predispose an individual to appraise his or her circumstances in a pessimistic, anger-eliciting way. These appraisal tendencies were related to trait-anger, suggesting that they play an important role in trait-state relationships. Individual differences in appraisal can also be specific to particular contexts, as reflected by the person $\times$ situation interaction contributions to the studied appraisals (for a more elaborate discussion of these types of individual differences, see, e.g., Kuppens \& Van Mechelen, 2007).

However, our results also diverge from classic appraisal theory models of anger such as that proposed by Smith and Lazarus (1993). In the model of Smith and Lazarus (1993), motivational 
relevance, frustration, and other-accountability are seen as the relevant appraisals for anger, with other-blame emerging as the core, overarching relational theme characterizing the essence of the anger eliciting appraisal process. In contrast, our results clearly suggest that the appraisal of frustration is more essential to anger as compared to social appraisals in terms of other-blame, -accountability, or unfairness. This echoes earlier statements from, for instance, Frijda (1993) that the most elementary formulation of the eliciting conditions for anger can be described as acute frustration and that attribution of blame or the perception of norm transgression (unfairness) are of secondary importance in explaining anger. Indeed, Kuppens et al. (2007) previously demonstrated that whereas frustration is a necessary condition for anger for all persons, other-blame and unfairness are not.

In addition, the experience of anger was not invariably related to the different appraisals, which is indicated by the consistently observed individual differences in the relations between the appraisals and the experience of anger. Although such individual differences contributed to variability in anger to a much smaller extent, these findings also challenge assumptions held by some appraisal models such as that proposed by Smith and Lazarus (1993). In these models, such variation is not taken into consideration (see above), but emotions are rather seen as entities that are invariably associated with a fixed set of appraisals (Barrett, 2006; Kuppens et al., 2003). In contrast with such a position, our findings demonstrate that individual differences characterize the appraisal-emotion relationships and thus that the relationships between appraisals and emotional experience are not of an invariant nature. In this respect, our findings suggest that a statement such as "I feel angry" can mean different things for different individuals because people can differ in how strong specific appraisals correspond to this feeling.

Finally, the findings consistently indicated that individual difference sources independent of the included appraisals also contribute to anger experience. The fact that people show individual differences in anger experience independent of appraisal processes provides some support for nonappraisal theories of anger, such as the neoassociationistic theory of anger-elicitation promoted of Berkowitz (1990). Although it is clear that the major route to anger is via appraisal, our findings show that not all variability in anger can be explained by appraisal and that other processes should be considered to play a role as well. The role of 
trait-anger herein remains unclear, however, as our results in this respect were inconsistent across both studies.

The obtained results, nevertheless, shed light on our understanding of trait-anger, a trait that is related to several harmful outcomes such as aggression, coronary heart disease, (e.g., Spielberger et al., 1985), and essential hypertension (e.g., Spielberger et al., 1991). Our results consistently showed that high trait-anger individuals are primarily characterized by multiple appraisal process distortions that cause them more easily to appraise events in anger-eliciting, pessimistic ways. This finding links with previous findings regarding hostile attribution bias (e.g., Epps \& Kendall, 1995; Graham, 1997) and also broadens its conclusions to other anger-relevant appraisalcontents. Additionally, high trait-anger seemed to involve a lack of frustration tolerance (reflected in stronger relations between the experience of frustration and anger) and a higher likelihood of experiencing anger in the absence of wrongdoing caused by others (reflected in weaker relations between other-blame and anger).

\section{Implications for the Treatment of Anger Disorders}

The present results provide several indications about what type of interventions would be most successful in anger management programs. Following our findings, the most impactful intervention should be one that is aimed at altering an individual's appraisal of his or her circumstances. Such interventions should be aimed at altering maladaptive habitual appraisal tendencies such that individuals become less likely to interpret events as frustrating and unfair and the actions of others as blameworthy. The contribution of the person by situation interaction further underscores the importance of identifying the specific types of situations that are most vulnerable to be interpreted in anger-eliciting ways. Of lesser impact, intervention programs could also aim at changing the way one emotionally reacts to specific appraisals. For instance, learning to deal with frustration and efforts to make anger experience more contingent on other's blameworthy actions should heighten one's threshold for anger.

\section{A Framework to Disentangle Contributions in Sequential Processes}

In psychological science, many theories explicitly or implicitly rely on the assumption of sequential processes to explain psychological 
outcomes or behavior (e.g., theory of planned behavior, Ajzen, 1991; social-cognitive personality theory, Mischel \& Shoda, 1995). Common to such theories is that an outcome is assumed to result from a psychological process that involves a number of mediating variables. Accordingly, variability in the outcome is a function of variability in the different links of the hypothesized sequential processes. Information on the location of the most important sources of variability and their nature is crucial for the prediction, understanding, and intervention towards the outcome of interest. With suited data, the framework presented in this article provides a method to disentangle these different contributions and may be applied to a wide variety of psychological phenomena. It should be noted that an important consideration in this approach regards the selection of mediating variables (in our context, appraisals). In particular, the estimated contribution of the different sources of individual differences can be affected by selecting mediating variables that are psychologically "further" or "closer" to the outcome of interest, and this has to be held in mind when selecting appropriate mediating variables. ${ }^{5}$

\section{Limitations and Conclusions}

A limitation of the findings is that they are based on responses to hypothetical situations. Despite possible disadvantages of such a method, no other method is readily available to obtain appraisal and emotional experience information from all participants in reaction to a sufficiently large set of standardized contexts - information that is needed to obtain reliable estimates of the contributions of the different sources of variance. Second, our current analytical strategy only allows considering linear relationships between appraisals and emo-

5. In the present context, how appraisal items are formulated may play a role. For instance, an appraisal item formulated in terms of frustration could be considered to have a more affective connotation than an item formulated in terms of goal blockage and may thus be more proximal to anger. As a result, there may, for instance, be less room for individual differences in the relation between frustration and anger than in the relation between goal blockage and anger, and this may affect how much variance is attributed to the different sources of individual differences. Subsidiary analyses showed that this was not the case, however. Including an item in terms of goal blockage instead of in terms of frustration in Study 2 (where an item in terms of goal blockage was assessed but was not further reported on in the present context because of parsimony) did not cause substantial changes in the relative contributions of sources of individual differences. 
tional experience. It is possible that some appraisal-emotion relationships - although likely monotonic - may not be of a linear form (but, for instance, involve a crucial threshold). Unfortunately, however, including such relationships would strongly increase the mathematical complexity of our approach, and we therefore chose not to incorporate nonlinear relationships into our model. A final important limitation stems from the correlational nature of the presented data. Although appraisals are generally ascribed the pivotal role in emotion elicitation and there is experimental evidence to back these claims (e.g., Neumann, 2000; Roseman \& Evdokas, 2004), our current findings should be interpreted in terms of associations between appraisals and emotional experience and not in causal terms.

To conclude, findings from two different studies concluded that individual differences in anger experience are most strongly determined by individual differences in how people appraise their environment. This supports the main assumption of appraisal theories of emotions. Yet variability in anger experience is to a lesser extent also due to how strong these appraisals are associated with anger experience and to sources of individual differences outside the appraisal pathway. Finally, our results suggest that frustration, rather than other-blame or social appraisals of other's wrongdoing, should be regarded as the most defining appraisal of anger.

\section{REFERENCES}

Ajzen, I. (1991). The theory of planned behavior. Organizational Behavior and Human Decision Processes, 50, 179-211.

Anderson, C. A., \& Bushman, B. J. (2002). Human aggression. Annual Review of Psychology, 53, 27-51.

Averill, J. R. (1983). Studies on anger and aggression: Implications for theories of emotion. American Psychologist, 38, 1145-1160.

Barrett, L. F. (2006). Are emotions natural kinds? Perspectives on Psychological Science, 1, 28-58.

Bettencourt, B. A., Talley, A., Benjamin, A. J., \& Valentine, J. (2006). Personality and aggressive behaviour under provoking and neutral conditions: A metaanalytic review. Psychological Bulletin, 132, 751-777.

Berkowitz, L. (1990). On the formation and regulation of anger and aggression: A cognitive-neoassociationistic analysis. American Psychologist, 45, 494-503.

Berkowitz, L., \& Harmon-Jones, E. (2004). Toward an understanding of the determinants of anger. Emotion, 4, 107-130.

Bock, R. D. (1975). Multivariate statistical methods in behavioral research. New York: McGraw-Hill. 
Bray, J. H., \& Maxwell, S. E. (1985). Multivariate analysis of variance. Sage University paper series on quantitative research methods (Vol. 54). Newbury Park, CA: Sage.

Buss, A. H. (2004). Anger, frustration, and aversiveness. Emotion, 4, 131-132.

Deffenbacher, J. L. (1992). Trait anger: Theory, findings, and implications. In C. D. Spielberger \& J. N. Butcher (Eds.), Advances in personality assessment (Vol. 9, pp. 177-201). Hillsdale, NJ: Lawrence Erlbaum.

Dodge, K. A. (1993). Social-cognitive mechanisms in the development of conduct disorder and depression. Annual Review of Psychology, 44, 559-584.

Dollard, J., Doob, L., Miller, N., Mowrer, O., \& Sears, R. (1939). Frustration and aggression. New Haven, CT: Yale University Press.

Ellsworth, P. C., \& Tong, E. M. W. (2006). What does it mean to be angry at yourself? Categories, appraisals, and the problem of language. Emotion, 6, $572-586$.

Epps, J., \& Kendall, P. C. (1995). Hostile attributional bias in adults. Cognitive Therapy and Research, 19, 159-178.

Fehr, B., Baldwin, M. W., Collins, L., Patterson, S., \& Benditt, R. (1999). Anger in close relationships: An interpersonal script analysis. Personality and Social Psychology Bulletin, 25, 299-312.

Frijda, N. H. (1993). The place of appraisal in emotion. Cognition and Emotion, 7, $357-387$.

Frijda, N. H., Kuipers, P., \& ter Schure, E. (1989). Relations among emotion, appraisal, and emotional action readiness. Journal of Personality and Social Psychology, 57, 212-228.

Frijda, N. H., \& Zeelenberg, M. (2001). Appraisal: what is the dependent? In K. R. Scherer, A. Schorr, \& T. Johnstone (Eds.), Appraisal processes in emotion: Theory, methods, research (pp. 141-156). New York: Oxford University Press.

Graham, S. (1997). Using attribution theory to understand social and academic motivation in African American youth. Educational Psychologist, 32, 21-34.

Griner, L. A., \& Smith, C. A. (2000). Contributions of motivational orientation to appraisal and emotion. Personality and Social Psychology Bulletin, 26, 727-740.

Gross, J. J., \& John, O. P. (2003). Individual differences in two emotion regulation processes: Implications for affect, relationships, and well-being. Journal of Personality and Social Psychology, 85, 348-362.

Kuppens, P., \& Van Mechelen, I. (2007). Interactional appraisal models for the anger appraisals of threatened self-esteem, other-blame, and frustration. Cognition and Emotion, 21, 56-77.

Kuppens, P., Van Mechelen, I., Smits, D. J. M., \& De Boeck, P. (2003). The appraisal basis of anger: Specificity, necessity and sufficiency of components. Emotion, 3, 254-269.

Kuppens, P., Van Mechelen, I., Smits, D. J. M., De Boeck, P., \& Ceulemans, E. (2007). Individual differences in patterns of appraisal and anger experience. Cognition and Emotion, 21, 689-713.

Larsen, R. J., \& Ketelaar, T. (1991). Personality and susceptibility to positive and negative states. Journal of Personality and Social Psychology, 61, 132-140. 
Lazarus, R. S. (1994). Individual differences in emotion. In P. Ekman \& R. J. Davidson (Eds.), The nature of emotion: Fundamental questions (pp. 332-336). New York: Oxford University Press.

Leach, C. W., Iyer, A., \& Pedersen, A. (2006). Anger and guilt about in-group advantage explain the willingness for political action. Personality and Social Psychology Bulletin, 32, 1232-1245.

Martin, R. C., \& Dahlen, E. R. (2004). Irrational beliefs and the experience and expression of anger. Journal of Rational Emotive and Cognitive Behavior Therapy, 22, 3-20.

Meier, B. P., \& Robinson, M. D. (2004). Does quick to blame mean quick to anger? The role of agreeableness in dissociating blame and anger. Personality and Social Psychology Bulletin, 30, 856-867.

Meier, B. P., Robinson, M. D., \& Wilkowski, B. M. (2006). Turning the other cheek: Agreeableness and the regulation of aggression-related primes. Psychological Science, 17, 136-142.

Mischel, W., \& Shoda, Y. (1995). A cognitive-affective system theory of personality: Reconceptualizing situations, dispositions, dynamics, and invariance in personality structure. Psychological Review, 102, 246-268.

Molenberghs, G., \& Verbeke, G. (2004). An introduction to generalized (non)linear mixed models. In P. De Boeck \& M. Wilson (Eds.), Explanatory item response models. A generalized linear and nonlinear approach (pp. 111-153). Springer: New York.

Neumann, R. (2000). The causal influence of attributions on emotions: A procedural priming approach. Psychological Science, 11, 179-183.

Nezlek, J. B. (2001). Multilevel random coefficient analyses of event- and intervalcontingent data in social and personality psychology research. Personality and Social Psychology Bulletin, 27, 771-785.

Nezlek, J. B., Van Mechelen, I., Vansteelandt, K., \& Kuppens, P. (2008). Appraisal-emotion relationships in daily life. Emotion, 8, 145-150.

Omdahl, B. L. (1995). Cognitive appraisal, emotion and empathy. Mahwah, NJ: Lawrence Erlbaum.

Parkinson, B. (1999). Relations and dissociations between appraisal and emotion ratings of reasonable and unreasonable anger and guilt. Cognition and Emotion, 13, 347-385.

Parkinson, B. (2001). Putting appraisal in context. In K. R. Scherer, A. Schorr, \& T. Johnstone (Eds.), Appraisal processes in emotion: Theory, methods, research (pp. 173-186). New York: Oxford University Press.

Robinson, M. D., \& Clore, G. L. (2001). Simulation, scenarios, and emotional appraisal: Testing the convergence of real and imagined reactions to emotional stimuli. Personality and Social Psychology Bulletin, 27, $1520-1532$.

Roseman, I. J., \& Evdokas, A. (2004). Appraisals cause experienced emotions: Experimental evidence. Cognition and Emotion, 18, 1-28.

Roseman, I. J., \& Smith, C. A. (2001). Appraisal theory: Overview, assumptions, varieties, controversies. In K. R. Scherer, A. Schorr, \& T. Johnstone (Eds.), Appraisal processes in emotion: Theory, methods, research (pp. 3-19). New York: Oxford University Press. 
Roseman, I. J., Spindel, M. S., \& Jose, P. E. (1990). Appraisals of emotion-eliciting events: Testing a theory of discrete emotions. Journal of Personality and Social Psychology, 59, 899-915.

Russell, J. A., \& Fehr, B. (1994). Fuzzy concepts in a fuzzy hierarchy: Varieties of anger. Journal of Personality and Social Psychology, 67, 186-205.

Scherer, K. R. (1999). Appraisal theory. In T. Dalgleish \& M. Power (Eds.), Handbook of cognition and emotion (pp. 637-664). Chichester, UK: Wiley \& Sons.

Scherer, K. R. (2001a). The nature and study of appraisal: A review of the issues. In K. R. Scherer, A. Schorr, \& T. Johnstone (Eds.), Appraisal processes in emotion: Theory, methods, research (pp. 369-392). New York: Oxford University Press.

Scherer, K. R. (2001b). Appraisal considered as a process of multilevel sequential checking. In K. R. Scherer, A. Schorr, \& T. Johnstone (Eds.), Appraisal processes in emotion: Theory, methods, research (pp. 92-120). New York: Oxford University Press.

Scherer, K. R., Schorr, A., \& Johnstone, T. (2001). Appraisal processes in emotion: Theory, methods, research. New York: Oxford University Press.

Silvia, P. J. (2005). Cognitive appraisals and interest in visual art: Exploring appraisal theory of aesthetic emotions. Empirical Studies of the Arts, 23, 119-133.

Smith, C. A., \& Ellsworth, P. C. (1985). Patterns of cognitive appraisal in emotion. Journal of Personality and Social Psychology, 48, 813-838.

Smith, C. A., \& Kirby, L. D. (2001). Toward delivering on the promise of appraisal theory. In K. R. Scherer, A. Schorr, \& T. Johnstone (Eds.), Appraisal processes in emotion: Theory, methods, research (pp. 121-140). New York: Oxford University Press.

Smith, C. A., \& Lazarus, R. S. (1993). Appraisal components, core relational themes, and the emotions. Cognition and Emotion, 7, 233-269.

Smith, C. A., \& Pope, L. K. (1992). Appraisal and emotion: The interactional contributions of dispositional and situational factors. In M. S. Clark (Ed.), Review of personality and social psychology, Volume 14: Emotion and social behavior (pp. 32-62). Newbury Park, CA: Sage.

Snijders, T. A. B., \& Bosker, R. J. (1999). Multilevel analysis: An introduction to basic and advanced multilevel modeling. London: Sage.

Spielberger, C. D., Crane, R. S., Kearns, W. D., Pellegrin, K. L., Rickman, R. L., \& Johnson, E. H. (1991). Anger and anxiety in essential hypertension. In C. D. Spielberger, I. G. Sarason, Z. Kulcsar, \& G. L. VanHeck (Eds.), Stress and emotion: Anxiety, anger, and curiosity (Vol. 14, pp. 265-283). Washington: Hemisphere.

Spielberger, C. D., Johnson, E. H., Russell, S. F., Crane, R. J., Jacobs, G. A., \& Worden, T. J. (1985). The experience and expression of anger: Construction and validation of an anger expression scale. In M. A. Chesney \& R. H. Rosenman (Eds.), Anger and hostility in cardiovascular and behavioral disorders (pp. 5-30). New York: Hemisphere.

Tiedens, L. Z. (2001). Anger and advancement versus sadness and subjugation: The effect of negative emotion expressions on social status conferral. Journal of Personality and Social Psychology, 80, 86-94. 
van der Ploeg, H. M., Defares, P. B., \& Spielberger, C. D. (1982). Zelf-analyse vragenlijst [Trait-anger Scale] Lisse, The Netherlands: Swets \& Zeitlinger.

van Reekum, C. M., \& Scherer, K. R. (1997). Levels of processing in emotionantecedent appraisal. In G. Matthews (Ed.), Cognitive science perspectives on personality and emotion (pp. 259-300). Amsterdam: Elsevier Science.

Vansteelandt, K., \& Van Mechelen, I. (2006). Individual differences in anger and sadness: In pursuit of active situational features and psychological processes. Journal of Personality, 74, 871-910.

Wilkowski, B. M., \& Robinson, M. D. (2007). Keeping one's cool: Trait anger, hostile thoughts, and the recruitment of limited capacity control. Personality and Social Psychology Bulletin, 33, 1201-1213.

\section{APPENDIX A}

Summary descriptions of situation vignettes used in Study 1, grouped according to the instructions under which they were generated by the participants in the study by Kuppens et al. (2003).

\section{Frustration present}

The waiter doesn't show up when you're sitting in a café.

You're in love with someone, but he/she is not interested in you.

Frustration absent

Your sports team loses to a much higher ranked team.

Your sibling wakes up with a high fever in the morning.

Other-accountability present

You are blamed for someone else's failures after a sports match. A fellow student loses your notes, causing you to fail the exam.

Other-accountability absent

You drop a plate of glasses at a party, and everyone is looking at you.

A floppy disk holding an important school assignment is destroyed by your computer.

Arrogant entitlement present

Your sibling sneaks out when you both have to clean up the house. Being a job student yourself, an employee makes you do all his chores.

Arrogant entitlement absent

Your sibling is nearly run over by a car when he/she runs into the street.

You're alone at home, and you're bored. 
Antagonistic action tendency present

No one lets an old man sit down on a crowded bus.

A fellow student fails to return your notes the day before an exam.

Antagonistic action tendency absent

After working hard on an assignment, your teacher says it's still not better than your previous work.

You and a friend are both in love with the same person.

Anger present

You're at a party, and someone tells you that a friend outside has smashed your bike.

You hear that a friend is spreading gossip about you.

Anger absent

You rip your pants during sports.

Your friend is in a coma after an accident.

Irritation present

It's hard to study when the neighbors make a lot of noise and it's a hot day.

A friend lets you down on an appointment to go out with his/her friend.

Irritation absent

You fail on a test, on which the average score is 3/10.

A swimming appointment is cancelled because one of your friends falls ill.

\section{APPENDIX B}

Summary descriptions of situation vignettes used in Study 2, grouped according to how they were originally designed to elicit potential anger appraisals of frustration, accountability, disrespect, hostile intentions, self-relevance, and coping potential.

Frustration in achievement situation

Your clock failed to wake you up in the morning, and you miss the final class of a course.

You have a group assignment with some fellow students. They don't work hard, and you all get a bad grade.

Frustration in affiliation situation

Your roommates went to the movies without informing you.

You miss a popular party because you fall asleep at home.

Accountability is clear 
You arrange with your roommates that each in turn has to put out the garbage. When it someone else's turn, you noticed that he/she didn't clean up.

You didn't study hard enough for an exam, and you fail the exam. Accountability is ambiguous

On holiday with friends, you arrange that each, in turn, has to carry the heavy tent gear. One day, the tent gear is missing. You are fired from your holiday job.

Disrespect is clearly present or absent A friend returns your CD-player, claiming that everything is $O K$, but it turns out to be broken afterwards.

You are hit on your bike by another biker. He/she apologizes and proposes to pay back the damage to your bike.

Disrespect is ambiguous

A fellow student fails to return your notes when you need them for studying.

You bump into someone on the street.

Hostile intentions are clearly present or absent

The waiter in a restaurant informs you that it may take a while before you can eat because it is a busy evening. Finally, you are served after 50 minutes of waiting.

A friend lets you down on a date, and calls you the following day to let you know that he/she didn't feel like meeting with you and went out with other people instead.

Hostile intentions are ambiguous

You're out for a drink after a hard day's work, and you have to wait 30 minutes before you are served.

You arrange with a good friend to go out together, and he/she will contact you to meet each other. You don't hear from him/her.

Self-relevant implications

You are in love with someone, but he/she is more interested in someone else.

You hear that a friend is spreading gossip about you.

No self-relevant implications

Your friend is in a coma after an accident.

A swimming appointment is cancelled because one of your friends falls ill.

Coping potential present

You have arranged for a hotel room with sea view. Upon arrival, you are given a room without sea view. 
Upon leaving class, you notice that a police officer is removing your bike because it was illegally parked.

Coping potential absent

You are hit by a car on your way to an important appointment, causing you to miss the appointment.

A floppy disk holding an important school assignment is destroyed by your computer. 